\title{
Effect of adhesion promoting monomer addition to MMA-TBBO resin on bonding to pure palladium
}

\author{
Hiroyuki MINAMI ${ }^{1}$, Sadaaki MURAHARA ${ }^{2}$, Koichi MURAGUCHI ${ }^{1}$, Kenji SAKOGUCHI², Shiro SUZUKI ${ }^{3}$ \\ and Takuo TANAKA2 \\ ${ }^{1}$ Fixed Prosthetic Clinic, Kagoshima University Medical and Dental Hospital, 8-35-1 Sakuragaoka, Kagoshima 890-8544, Japan \\ ${ }^{2}$ Department of Fixed Prosthetic Dentistry, Graduate School of Medical and Dental Sciences, Kagoshima University, 8-35-1 Sakuragaoka, Kagoshima \\ 890-8544, Japan \\ ${ }^{3}$ Department of Prosthodontics, University of Alabama at Birmingham, School of Dentistry, 1919 7th Ave. South, Birmingham, Alabama 35294-0007, \\ USA \\ Corresponding author, Hiroyuki MINAMI; E-mail: minami@dent.kagoshima-u.ac.jp
}

\begin{abstract}
This study evaluated the effects of combined use of metal primers and modified monomers on the bonding of MMA-TBBO resins to pure palladium $(\mathrm{Pd})$. Bonding surface was polished with 600-grit silicon carbide paper and primed with one of these four metal primers: V-Primer, M.L. Primer, Metaltite, or Alloy Primer. Four monomers, including three modified ones, were added to MMATBBO resin. One was a methyl methacrylate monomer containing no adhesion promoting monomers, while the other two modified monomers contained the functional monomer of either V-Primer or Alloy Primer. Bonded specimens were prepared by incremental build-up of MMA-TBBO resin on primed Pd surfaces. Shear bond strengths were measured after thermal cycling. Bonding to Pd was significantly improved when modified monomer containing the functional monomer of Alloy Primer was used in combination with M.L. Primer or Metaltite applied on the bonding surface.
\end{abstract}

Keywords: MMA-TBBO resin, Adhesion promoting monomer, Pure palladium, Modified monomer, Shear bond strength

\section{INTRODUCTION}

Resin-bonded fixed partial dentures with cast metal frameworks have emerged as a minimally invasive, aesthetically pleasing, and predictable treatment option for abutment teeth ${ }^{1-3)}$. Two key factors contribute to this emerging trend: improvement in retainer $\operatorname{design}^{4-6)}$ and availability of metal primers which react directly and chemically with the bonding surfaces of noble metal alloys, such as silver-containing gold-palladium alloys ${ }^{7,8)}$ and type IV gold alloy ${ }^{8-10)}$.

Noble metal alloys are not suitable for cases that require high-quality aesthetic appearance. To satisfy both aesthetic and functional demands, the optimal alternative is resin-bonded fixed partial dentures fabricated with metal alloy frameworks and porcelainfaced pontics. Traditionally, nickel-chromium ${ }^{11-13)}$ and cobalt-chromium ${ }^{12,14)}$ alloys are used for the retainers. This is largely because of well-established, durable bonding of adhesive resin cements to nickel-chromium ${ }^{15,16)}$ and cobalt-chromium ${ }^{17,18)}$ alloys. However, noble metal ceramic alloys are preferable and superior in terms of castability, workability, corrosion resistance, and biocompatibility ${ }^{19,20)}$.

Macro-mechanical retention and micro-mechanical retention are two critical factors that influence the clinical success and longevity of fixed partial dentures. Macro-mechanical retention depends on abutment preparation and precision of fit of retainers. Micromechanical retention is achieved by chemical bonding, which in turn can be achieved with surface modification of metal substrates or application of metal primers ${ }^{7-10)}$.
On the former, currently available surface treatment methods range from tin (Sn) plating ${ }^{13,21,22)}$ to thermal silica coating (Silicoater MD) ${ }^{22}$ ) and tribochemical silica coating (Rocatec) ${ }^{23)}$. On the latter, adhesion promoting monomers play an important role in improving bonding, which is especially vital for restorations with compromised retention form.

For base metals, it was shown that the presence of both TBBO initiator and 4-META functional monomer at the resin-metal interface during the setting reaction improved the bonding to cobalt-chromium alloy ${ }^{18)}$. For noble metals, inclusion of thiirane monomers as an adhesive monomer component of MMA-TBBO resin improved the bonding to dental precious metal alloys ${ }^{24)}$. Studies ${ }^{25,26)}$ have also shown the positive effect of metal primers on the bonding of 4-META/MMA-TBBO resin to high-gold-content metal ceramic alloys. At the same time, these studies ${ }^{25,26)}$ revealed the inadequacy of these primers on bonding to pure palladium (Pd) and highpalladium-content metal ceramic alloys. Although some studies $^{7-9)}$ have reported on the efficacy of metal primers in improving the bond strength to Pd-containing alloys, it must be highlighted that these alloys contained other metals such as $\mathrm{Ag}$ and $\mathrm{Cu}$, which are compatible with numerous primers ${ }^{25)}$.

The purpose of this study was to evaluate the effect of adhesion promoting monomers on bonding of MMA-TBBO resin to $\mathrm{Pd}$. Although pure $\mathrm{Pd}$ is not used clinically, it was employed in this study to investigate how to improve the bonding of adhesive resins to highpalladium-content alloys. Shear bond strengths of MMATBBO resins containing different adhesion promoting 
monomers to $\mathrm{Pd}$ were evaluated after thermal cycling. The null hypothesis was that the presence of adhesion promoting monomer derived from commercial metal primers would have no effect on the bonding of MMATBBO resin to $\mathrm{Pd}$.

\section{MATERIALS AND METHODS}

\section{Metal primers and $\mathrm{Pd}$ adherends}

Table 1 lists the materials used in this study. Figure 1, on the other hand, is a flow diagram which illustrates the sequence of steps entailed in preparing the bonded specimens for shear bond strength test, using the materials listed in Table 1.
Pd disks $(10 \times 2.5 \mathrm{~mm})$ of $>99.9 \%$ purity were provided by a manufacturer (Kojundo Chemical Laboratory Co., Ltd., Saitama, Japan) and used as the adherends. Bonding surface of each Pd adherend was polished using 600-grit silicon carbide paper (CarbiMet Paper Discs, Buehler, Lake Bluff, IL, USA) with ample water coolant. After ultrasonic cleaning in distilled water for $10 \mathrm{~min}$, $\mathrm{Pd}$ adherends were dried with filtered air.

\section{Modified monomers}

Table 2 lists the four kinds of monomers added to MMATBBO resin: proprietary Super-Bond monomer (Sun Medical Co., Ltd., Shiga, Japan), a methyl methacrylate monomer (MMA; Wako Pure Chemical Industries, Ltd.,

Table 1 Materials used in this study

\begin{tabular}{lcclc}
\hline \multicolumn{1}{c}{ Material } & Brand name & Composition & Manufacturer \\
\hline $\begin{array}{l}\text { Adherend material } \\
\text { Pure palladium }\end{array}$ & Pure Pd & $\operatorname{Pd}(>99.9 \%$ purity) & $\begin{array}{c}\text { Kojundo Chemical Laboratory Co., Ltd., } \\
\text { Saitama, Japan }\end{array}$ \\
\hline $\begin{array}{l}\text { Metal Primers } \\
\text { Single-liquid primer }\end{array}$ & Alloy Primer & VBATDT, MDP, Acetone & $\begin{array}{c}\text { Kuraray Noritake Dental Inc., Tokyo, } \\
\text { Japan }\end{array}$ \\
Single-liquid primer & Metaltite & MTU-6, Ethanol & 0371AA \\
Single-liquid primer & M.L. Primer & MDDT, 6-MHPA, Acetone & Shama Dental Corp., Tokyo, Japan \\
Single-liquid primer & V-Primer & VBATDT, Acetone & Sun Medical Co., Ltd., Shiga, Japan \\
\hline
\end{tabular}

VBATDT: 6-(4-vinylbenzyl-n-propyl)amino-1,3,5-triazine-2,4-dithiol

MDP: 10-methacryloyloxydecyl dihydrogen phosphate

MTU-6: 6-methacryloyloxyhexyl 2-thiouracil-5-carboxylate

MDDT: 10-methacryloyloxydecyl-6,8-dithiooctanoate

6-MHPA: 6-methacryloyloxyhexyl phosphonoacetate

Priming for bonding surface

Polishing of Pd adherend with \#600 silicon carbide paper

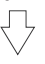

Application of 1 out of 5 metal primers onto polished Pd surface

\begin{tabular}{l|l|l|l}
\hline 1. Non-primed 2. V-Primer 3. M.L. Primer 4. Metaltite 5. Alloy Primer &
\end{tabular}

Mixing of MMA-TBBO resin

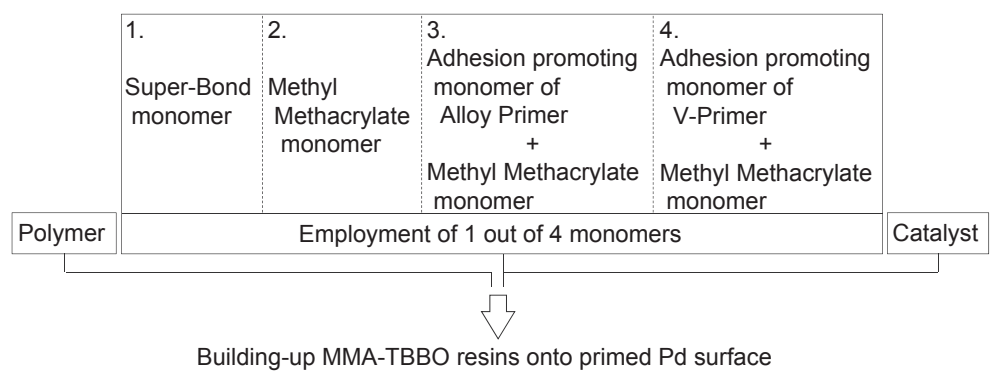

Fig. 1 Flow diagram of preparing bonded specimens for shear bond strength test. 
Osaka, Japan) which did not contain any adhesion promoting monomers, and two kinds of modified monomers derived from commercial metal primers.

To prepare the two modified monomers, a single drop of V-Primer (Sun Medical Co., Ltd., Shiga, Japan) or Alloy Primer (Kuraray Noritake Dental Inc., Tokyo, Japan) was placed in a ceramic mixing dish. The solvent (acetone) was completely evaporated by mild blowing of filtered air. Finally, four drops of MMA monomer were added to complete the preparation process of these two modified monomers (Fig. 1). Figure 2 shows the chemical structures of the adhesive monomers employed in the present study.

\section{Priming and bonding procedures}

Each Pd bonding surface was primed using one of the four commercial metal primers (Table 1). After a single drop of primer was applied on the Pd surface, it was dried with filtered air for $5 \mathrm{~s}$. Non-primed Pd adherends were used as controls (Fig. 1).

A 30- $\mu \mathrm{m}$-thick tape (Mending Tape, Kokuyo Co., Ltd., Osaka, Japan) with a 5-mm-diameter opening was placed on the primed/non-primed bonding surface to define the bonding area. Bonding area was covered with a brass ring of $6 \mathrm{~mm}$ inner diameter and $2.5 \mathrm{~mm}$ height.

A single drop of TBBO polymerization catalyst was added to each monomer (Fig. 1). Each MMA-TBBO resin

Table 2 MMA-TBBO resins used in this study

\begin{tabular}{|c|c|c|c|c|}
\hline Material & Brand name & Composition & Manufacturer & Batch number \\
\hline Polymer & Super-Bond polymer & PMMA & Sun Medical Co., Ltd., Shiga, Japan & EF22 \\
\hline \multirow{4}{*}{ Monomer } & Super-bond monomer & MMA, 4-META & Sun Medical Co., Ltd., Shiga, Japan & EF3 \\
\hline & $\begin{array}{l}\text { Methyl Methacrylate } \\
\text { Monomer }\end{array}$ & MMA & $\begin{array}{l}\text { Wako Pure Chemical Industries, Ltd., } \\
\text { Osaka, Japan }\end{array}$ & EPK3235 \\
\hline & $\begin{array}{l}\text { Alloy Primer+MMA } \\
\text { monomer }\end{array}$ & VBATDT, MDP, MMA & - & - \\
\hline & $\begin{array}{l}\text { V-Primer+MMA } \\
\text { monomer }\end{array}$ & VBATDT, MMA & - & \\
\hline Catalyst & Super-Bond catalyst & TBBO, Acetone & Sun Medical Co., Ltd., Shiga, Japan & EE1F \\
\hline
\end{tabular}

PMMA: polymethyl methacrylate

MMA: methyl methacrylate

4-META: 4-methacryloyloxyethyl trimellitate anhydride

TBBO: tri- $n$-butylborane oxide

VBATDT<smiles>C=Cc1ccc(CN(CC)c2nc(=S)[nH]c(=S)[nH]2)cc1</smiles>

MDP

$\begin{array}{cc}\mathrm{I}_{3} \\ \mathrm{CH}_{2}=\mathrm{C}-\mathrm{C}-\mathrm{O}-\left(\mathrm{CH}_{2}\right)_{10}-\mathrm{O}-\mathrm{I} \\ \mathrm{O} & \mathrm{P}=\mathrm{O} \\ \mathrm{O} & \mathrm{OH}\end{array}$

MDDT

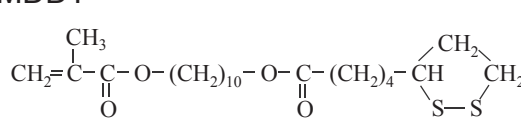

MHPA

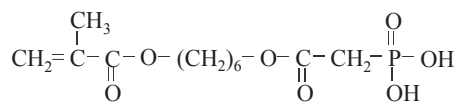

MTU-6

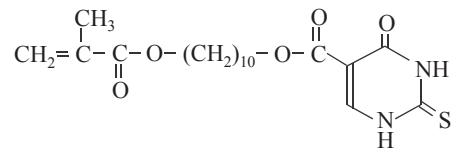

4-META

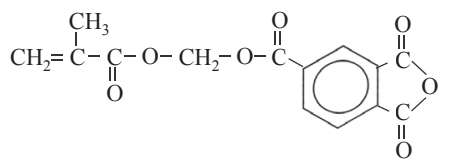

Fig. 2 Chemical structures of adhesive monomers employed in this study. 
was built up in small increments in the brass ring using a brush-dip technique (Fig. 3). A total of 100 bonded specimens were prepared for 20 groups, stemming from five types of primed/non-primed $\mathrm{Pd}$ adherends and four kinds of monomers added to MMA-TBBO resin. All specimens were kept at room temperature $\left(22 \pm 2^{\circ} \mathrm{C}\right)$ for $60 \mathrm{~min}$, followed by storage in $37^{\circ} \mathrm{C}$ distilled water for $24 \mathrm{~h}$.

\section{Shear bond strength test}

After 24-h water storage, specimens were subjected to 2,000 times of thermal cycling (Rika-Kogyo, Hachioji, Japan) by immersing in $5 \pm 1^{\circ} \mathrm{C}$ and $55 \pm 1^{\circ} \mathrm{C}$ water baths with 1-min dwell time at each temperature.

Shear bond strength (SBS) test was performed using a universal testing machine (AGS-5kNG, Shimadzu Corp., Kyoto, Japan) at $1.0 \mathrm{~mm} / \mathrm{min}$ crosshead speed until failure occurred. Figure 4 shows the cross-sectional view of the SBS test setup. A chisel-like, stainless steel

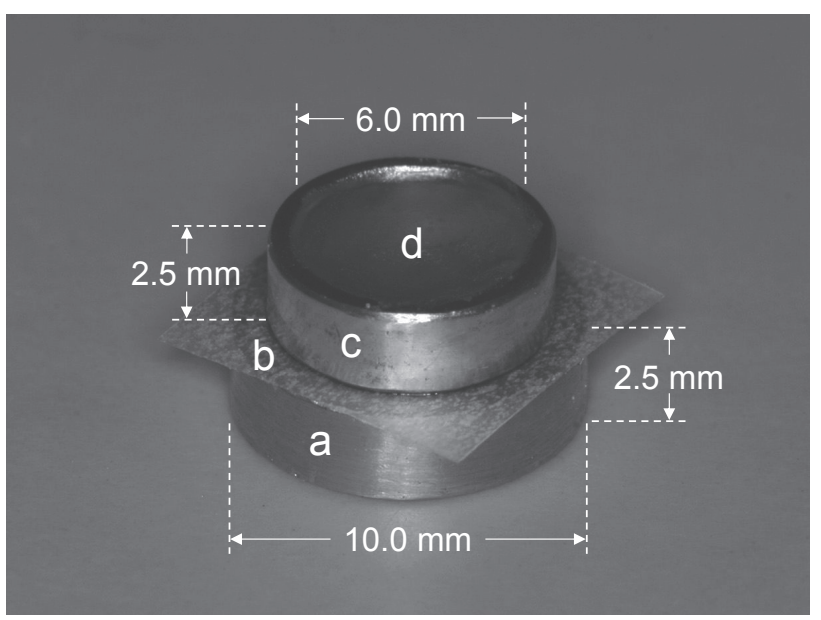

Fig. 3 Bonded specimen for shear bond strength test, where a: pure Pd adherend; b: masking tape; c: brass ring; and d: MMA-TBBO resin.

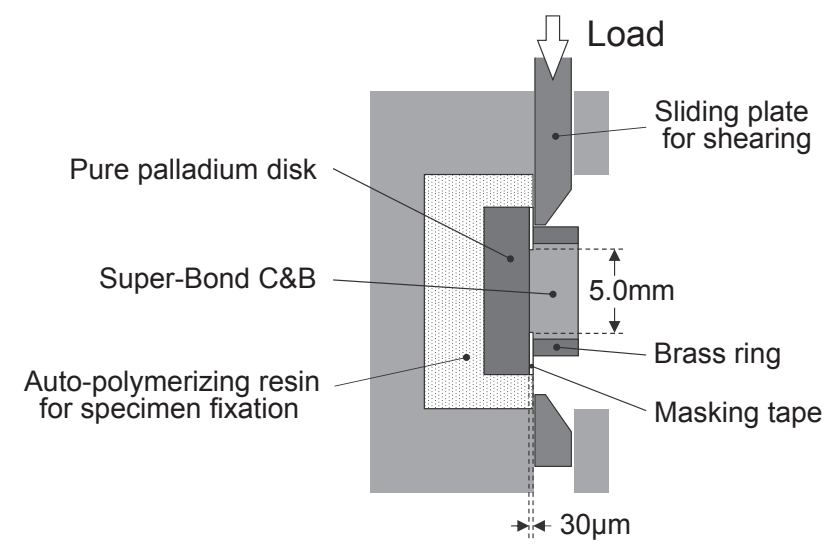

Fig. 4 Cross-sectional view of shear bond strength test setup. apparatus with a 0.5-mm-wide blunt edge was used to apply the shear force flush against the masking tape and parallel to the bonding interface between the $\mathrm{Pd}$ adherend and MMA-TBBO resin. SBS (MPa) was obtained by dividing the maximum load $(\mathrm{N})$ by the bonding area $\left(\mathrm{mm}^{2}\right)$.

\section{Statistical analysis}

Data were statistically analyzed using two-way analysis of variance (ANOVA) with the primer type and the kind of monomer added to MMA-TBBO resin as independent factors $(\alpha=0.05)$. Multiple comparisons were carried out using the Bonferroni-Dunn test to identify the significant differences among the groups $(\alpha=0.05)$.

\section{Failure analysis}

Debonded surface of each specimen was analyzed using an optical microscope (SMZ-10, Nikon Corp., Tokyo, Japan) at $\times 10$ magnification. Failure modes were classified as cohesive failure of MMA-TBBO resin, adhesive failure at adherend-resin interface, or mixed failure consisting of both cohesive and adhesive failures.

\section{RESULTS}

Figure 5 shows the mean SBSs of 20 groups evaluated in this study. Tables 3 and 4 show the statistical analysis results for SBSs among monomers and among metal primers respectively. Two-way ANOVA showed that there were significant differences among monomers $(p<0.0001)$ and among primers $(p<0.0001)$. There was also a significant interaction between primers and monomers $(p<0.0001)$ for SBS. One-way ANOVA results for monomers were $\mathrm{df}=3, \mathrm{~F}=17.0, p<0.0001$, Power=1.0;

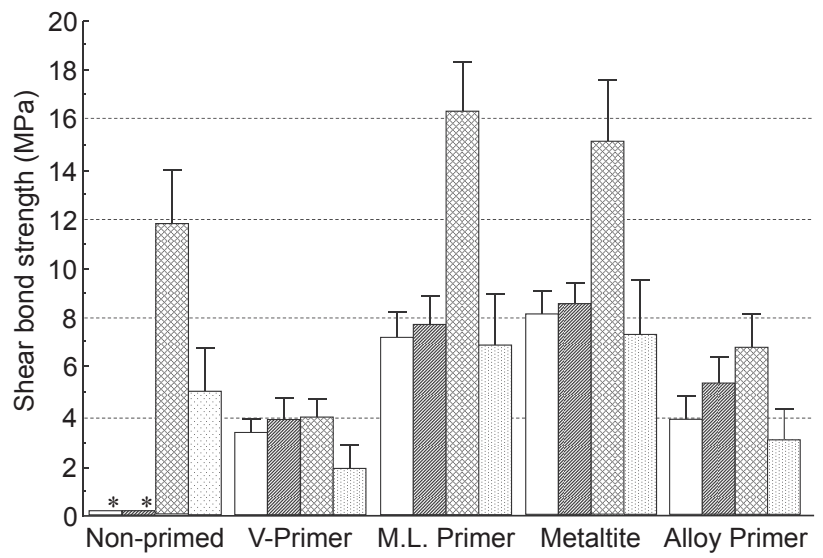

Fig. 5 Shear bond strengths to pure $\mathrm{Pd}$ adherends after 2,000 thermal cycles as function of monomer and metal primer types. Groups with asterisk (*) debonded during thermal cycling.

$\square$ Super-Bond monomer

MMA monomer

Alloy Primer+MMA monomer

V.Primer+MMA monomer 
Table 3 Statistical analysis results for shear bond strengths (MPa) among monomers within each metal primer group

\begin{tabular}{|c|c|c|c|}
\hline Priming for Pd surface & Monomers for MMA-TBBO resin & $\begin{array}{c}\text { Mean } \\
\text { (Standard Deviation) }\end{array}$ & $\begin{array}{l}\text { Difference within the } \\
\text { same primer groups }\end{array}$ \\
\hline \multirow{4}{*}{ Non-primed } & Super-Bond monomer & $0.0(0.0)$ & $\mathrm{A}$ \\
\hline & MMA & $0.0(0.0)$ & $\mathrm{A}$ \\
\hline & Alloy Primer+MMA & $11.8(2.0)$ & $\mathrm{B}$ \\
\hline & V-Primer+MMA & $5.0(1.8)$ & $\mathrm{C}$ \\
\hline \multirow{4}{*}{ V-Primer } & Super-Bond monomer & $3.3(0.6)$ & $\mathrm{D}$ \\
\hline & MMA & $3.8(0.9)$ & $\mathrm{D}$ \\
\hline & Alloy Primer+MMA & $3.9(0.8)$ & $\mathrm{D}$ \\
\hline & V-Primer+MMA & $1.9(0.9)$ & $\mathrm{D}$ \\
\hline \multirow{4}{*}{ M.L. Primer } & Super-Bond monomer & $7.2(1.0)$ & $\mathrm{E}$ \\
\hline & MMA & $7.7(1.1)$ & $\mathrm{E}$ \\
\hline & Alloy Primer+MMA & $16.3(2.0)$ & $\mathrm{F}$ \\
\hline & V-Primer+MMA & $6.9(2.0)$ & $\mathrm{E}$ \\
\hline \multirow{4}{*}{ Metaltite } & Super-Bond monomer & $8.1(0.9)$ & G \\
\hline & MMA & $8.6(0.9)$ & G \\
\hline & Alloy Primer+MMA & $15.1(2.3)$ & $\mathrm{H}$ \\
\hline & V-Primer+MMA & $7.3(2.2)$ & $\mathrm{G}$ \\
\hline \multirow{4}{*}{ Alloy Primer } & Super-Bond monomer & $3.9(0.8)$ & $\mathrm{I}, \mathrm{J}$ \\
\hline & MMA & $5.3(1.0)$ & $\mathrm{I}, \mathrm{J}$ \\
\hline & Alloy Primer+MMA & $6.8(1.4)$ & $J$ \\
\hline & V-Primer+MMA & $3.1(1.2)$ & $\mathrm{I}$ \\
\hline
\end{tabular}

The same uppercase letter denotes no significant difference among monomers within the same primer group.

Table 4 Statistical analysis results for shear bond strengths (MPa) among metal primers within each monomer group

\begin{tabular}{|c|c|c|c|}
\hline Priming for Pd surface & Monomer for MMA-TBBO resin & $\begin{array}{c}\text { Mean } \\
\text { (Standard Deviation) }\end{array}$ & $\begin{array}{l}\text { Difference within the } \\
\text { same monomer groups }\end{array}$ \\
\hline Non-primed & \multirow{5}{*}{ Super-Bond monomer } & $0.0(0.0)$ & $\mathrm{a}$ \\
\hline V-Primer & & $3.3(0.6)$ & $a, b$ \\
\hline M.L. Primer & & $7.2(1.0)$ & $\mathrm{c}, \mathrm{d}$ \\
\hline Metaltite & & $8.1(0.9)$ & $\mathrm{d}$ \\
\hline Alloy Primer & & $3.9(0.8)$ & $\mathrm{b}, \mathrm{c}$ \\
\hline Non-primed & \multirow{5}{*}{ MMA } & $0.0(0.0)$ & e \\
\hline V-Primer & & $3.8(0.9)$ & $\mathrm{f}$ \\
\hline M.L. Primer & & $7.7(1.1)$ & $\mathrm{g}$ \\
\hline Metaltite & & $8.6(0.9)$ & $\mathrm{g}$ \\
\hline Alloy Primer & & $5.3(1.0)$ & $f, g$ \\
\hline Non-primed & \multirow{5}{*}{ Alloy Primer+MMA } & $11.8(2.0)$ & $\mathrm{h}$ \\
\hline V-Primer & & $3.9(0.8)$ & i \\
\hline M.L. Primer & & $16.3(2.0)$ & $\mathrm{j}$ \\
\hline Metaltite & & $15.1(2.3)$ & $\mathrm{j}$ \\
\hline Alloy Primer & & $6.8(1.4)$ & $\mathrm{i}$ \\
\hline Non-primed & \multirow{5}{*}{ V-Primer+MMA } & $5.0(1.8)$ & $\mathrm{k}, \mathrm{l}$ \\
\hline V-Primer & & $1.9(0.9)$ & $\mathrm{k}$ \\
\hline M.L. Primer & & $6.9(2.0)$ & 1 \\
\hline Metaltite & & $7.3(2.2)$ & 1 \\
\hline Alloy Primer & & $3.1(1.2)$ & $\mathrm{k}$ \\
\hline
\end{tabular}

The same lowercase letter denotes no significant difference among primers within the same monomer group. 
for primers, the results were $\mathrm{df}=4, \mathrm{~F}=15.7, p<0.0001$, Power $=1.0$.

Statistical analysis for SBSs among monomers within each primer group

In the non-primed group, the specimens debonded during thermal cycling when Super-Bond monomer and MMA monomer were employed. In comparison, Alloy Primer+MMA monomer and V-Primer+MMA monomer yielded significantly higher $(p<0.0001)$ SBSs at 11.8 and $5 \mathrm{MPa}$ respectively (Fig. 5 and Table 3 ).

In V-Primer group, SBS ranged between 2 and 4 $\mathrm{MPa}$. There were no significant differences among the four monomers $(p>0.05)$ (Fig. 5 and Table 3).

In Alloy Primer group, there were no significant differences between Super-Bond and MMA monomers $(p>0.05)$. However, difference between Alloy Primer+MMA and V-Primer+MMA monomers was statistically significant ( $p=0.0001)$ (Fig. 5 and Table 3).

M.L. Primer and Metaltite groups showed similar results (Fig. 5 and Table 3). Highest SBS values (M.L. Primer: 16.3 MPa; Metaltite: 15.1 MPa) were obtained by using Alloy Primer+MMA monomer, which were significantly greater than the other three monomers $(p<0.0001)$. There were no significant differences among the remaining three monomers for both primers $(p>0.05)$.

Statistical analysis for SBSs among primers within each monomer group

In Super-Bond monomer group, application of M.L. Primer, Metaltite, and Alloy Primer yielded significantly higher SBSs than the non-primed specimens $(p<0.0001)$ (Fig. 5 and Table 4).

In MMA monomer group, all the primed specimens showed significantly higher SBSs than the non-primed specimens $(p<0.0001)$ (Fig. 5 and Table 4$)$.

In V-Primer+MMA monomer group, there were no statistically significant differences between primed and non-primed specimens $(p>0.05)$. Application of M.L. Primer and Metaltite yielded significantly higher SBSs than V-Primer- and Alloy Primer-treated specimens $(p<0.0001)$ (Fig. 5 and Table 4).

In Alloy Primer+MMA monomer group, SBSs of M.L. Primer-treated specimens (16.3 MPa) and Metaltitetreated specimens (15.1 MPa) were significantly greater compared to the non-primed specimens at $11.8 \mathrm{MPa}$ $(p<0.0001)$. In contrast, SBSs of V-Primer- and Alloy Primer-treated specimens were significantly lower than the non-primed specimens $(p<0.0001)$. There were no significant differences between M.L. Primer- and Metaltite-treated specimens and between V-Primerand Alloy Primer-treated specimens $(p>0.05)$ (Fig. 5 and Table 4).

\section{Debonding failure}

Both Non-primed/Super-Bond monomer and Nonprimed/MMA monomer specimens which debonded during thermal cycling showed adhesive failure. All other specimens exhibited mixed failure consisting

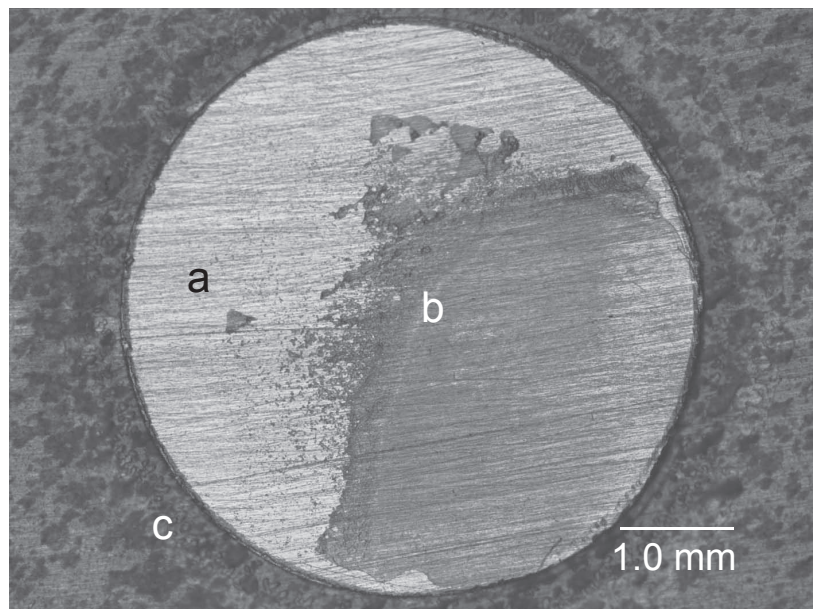

Fig. 6 Typical view of specimen showing mixed failure, where a: Pure Pd bonding surface showing adhesive failure; $b$ : MMA-TBBO resin remaining on $\mathrm{Pd}$ adherend; and c: Masking tape.

of both adhesive failure and cohesive failure of MMATBBO resin, whereby a thin layer of MMA-TBBO resin partially remained on the pure $\mathrm{Pd}$ adherend surface (Fig. 6).

\section{DISCUSSION}

The present study evaluated the effect of combined use of metal primers and modified monomers on the bonding of MMA-TBBO resins to pure Pd. This study served as a preliminary investigative study on improving the bonding of MMA-TBBO resins to high-palladiumcontent alloys. Therefore, the surfaces of pure $\mathrm{Pd}$ adherends were finished into regular flat surfaces with 600-grit silicon carbide papers to exclude the influence of mechanical retention, focusing only on the efficacy of each adhesion promoting monomer. In addition, a relatively small number of thermal cycles was employed so that results could be obtained in a short time period.

Results of the present study partially supported the null hypothesis. On the one hand, addition of 4-META to MMA monomer seemed to have no significant effect on bonding to Pd since both Super-Bond monomer and MMA monomer yielded almost similar SBS results within each metal primer group (Table 3). On the other hand, contradictions were observed in the SBS values of MMA-TBBO resins added with the adhesion promoting monomers of Alloy Primer. These SBS values ranked the highest among the other monomers when the bonding surface was primed with M.L. Primer or Metaltite (Fig. $5)$.

Adhesion promoting monomers are typically the primary component of surface treatment agents used to improve interfacial bonding to different kinds of metals. In adhesive resin formulations, they are also key constituents that play a dominant role. For example, 
the monomer liquid of Super-Bond C\&B adhesive resin cement contained 4-META, which was used as a control in the current study. Self-adhesive resins are increasingly being used in clinical practice, and they also contain adhesive monomers in their formulations. When an adhesion promoting monomer is included as an active ingredient in an adhesive resin formulation, a part of it is adsorbed on the adherend surface as well as the applied metal primer, and the remnant is copolymerized with the MMA monomer ${ }^{27}$.

\section{Efficacy of V-Primer+MMA monomer}

For the non-primed Pd surfaces, the use of V-Primer+MMA monomer significantly increased the SBS value compared to Super-Bond monomer and MMA monomer (Table 3). However, this value attained (5.0 MPa) was comparable to the performance of V-Primer+MMA monomer when used in combination with other metal primers (Table 4). Within V-Primer+MMA monomer group, SBSs attained with M.L. Primer- and Metaltite-treated surfaces were significantly higher than those treated with V-Primer and Alloy Primer. Both V-Primer and Alloy Primer contained VBATDT. These results implied that an excess amount of VBATDT might have an adverse effect on bonding to Pd.

An adhesion promoting monomer bears two different types of adhesion promoting groups in its molecular design. The tautomer type utilizes tautomerism -where a stable structure with the thione type (-NHCS-) is tautomerized to the reactive tautomer with a thiol type $(-\mathrm{N}=\mathrm{C}(\mathrm{SH})-)$ on a precious metal surface ${ }^{28)}$. Sulfur-containing monomers, such as triazinedithione (VBATDT, Fig. 2), belong to the tautomer type ${ }^{28}$. Within the V-Primer+MMA monomer group, the decreased SBSs of V-Primer- and Alloy Primer-treated specimens was probably due to the thiol compound inhibiting the polymerization of $\mathrm{MMA}^{24)}$.

\section{Efficacy of Alloy Primer+MMA monomer}

When Alloy Primer+MMA monomer was added to MMATBBO resin, the SBSs attained with both primed and non-primed Pd surfaces were significantly higher than those attained with V-Primer+MMA monomer, except for specimens applied with V-Primer (Table 4).

Alloy Primer contained both VBATDT and MDP. This seemed to indicate that MDP played a major role in bonding to $\mathrm{Pd}$. In a previous study ${ }^{25}$, it was shown that diverse metal primers containing different kinds of adhesion promoting monomers revealed affinity to different types of pure metals. Nonetheless, none of the primers, including M.L. Primer and Metaltite, was effective in bonding to pure $\mathrm{Pd}^{25)}$. Interestingly in this study, when Alloy Primer+MMA monomer was used in combination with M.L. Primer or Metaltite, the highest SBS values were obtained (Table 4), suggesting a significant bonding effectiveness to Pd. Therefore, the efficacy of adhesion promoting monomers contained in metal primers could be improved by being compatible with the adhesion promoting monomer(s) added to MMA-TBBO resins.
Within the Alloy Primer+MMA monomer group, comparison among the different types of primed surfaces revealed that the SBS of Alloy Primer-treated group was significantly lower than the non-primed group. This result could be caused by a twofold reason: the inhibitory effect of excessive amount of VBATDT on polymerization $^{24)}$ and the negative effect of $\mathrm{MDP}^{29)}$ when both functional monomers coexisted.

\section{Limitations of present study}

It must be put into perspective that the limitations of the present study's experimental design could have affected the efficacy of adhesion promoting monomers in promoting the bonding of MMA-TBBO resin to pure Pd.

First, a thin layer of adhesive resin cement was not achieved in this study as MMA-TBBO resin was filled into the brass ring placed on the Pd adherend. Therefore, further fatigue testing investigations based on reduced cement thicknesses are needed.

MDP monomer has a high affinity for ceramic materials ${ }^{30-32)}$. This meant that a certain amount of MDP might have reacted with the ceramic mixing dish. Besides, MDP monomer could have vaporized alongside the evaporation of organic solvent. Together, these phenomena most probably reduced the actual amount of MDP in the modified monomer since the preparation process entailed the evaporation of acetone. Therefore, to evaluate the efficacy of MDP monomer in bonding to pure $\mathrm{Pd}$, it might be expedient to use pure MDP solution in MMA monomer to prepare the modified monomer. This approach would also help to determine the optimal concentration of MDP to be used in clinically applicable bonding procedure.

\section{CONCLUSIONS}

This in vitro study evaluated the efficacy of adding modified monomers to MMA-TBBO resin on bonding to pure $\mathrm{Pd}$. Within the limitations of this study, it was concluded that bonding to pure $\mathrm{Pd}$ was significantly improved when modified monomer containing the functional monomers of Alloy Primer was used in combination with the application of M.L. Primer or Metaltite on pure Pd surface.

\section{REFERENCES}

1) Audenino G, Giannella G, Morello GM, Ceccarelli M, Carossa S, Bassi F. Resin-bonded fixed partial dentures: ten-year follow-up. Int J Prosthodont 2006; 19: 22-23.

2) Wyatt CC. Resin-bonded fixed partial dentures: what's new? J Can Dent Assoc 2007; 73: 933-938.

3) Barber MW, Preston AJ. An update on resin-bonded bridges. Eur J Prosthodont Restor Dent 2008; 16: 2-9.

4) Rammelsberg P, Pospiech P, Gernet W. Clinical factors affecting adhesive fixed partial dentures: a 6 -year study. J Prosthet Dent 1993; 70: 300-307.

5) el-Mowafy O, Rubo MH. Retention of a posterior resinbonded fixed partial denture with a modified design: an in vitro study. Int J Prosthodont 2000; 13: 425-431.

6) Goodacre CJ, Bernal G, Rungcharassaeng K, Kan JY. Clinical complications in fixed prosthodontics. J Prosthet Dent 2003; 
90: 31-41.

7) Yoshida K, Kamada K, Tanagawa M, Atsuta M. Shear bond strengths of three resin cements used with three adhesive primers for metal. J Prosthet Dent 1996; 75: 254-261.

8) Matsumura H, Kamada K, Tanoue N, Atsuta M. Effect of thione primers on bonding of noble metal alloys with an adhesive resin. J Dent 2000; 28: 287-293.

9) Antoniadou M, Kern M, Strub JR. Effect of a new metal primer on the bond strength between a resin cement and two high-noble alloys. J Prosthet Dent 2000; 84: 554-560.

10) Taira Y, Kamada K. Effects of primers containing sulfur and phosphate monomers on bonding type IV gold alloy. J Dent 2008; 36: 595-599.

11) Besimo C. Resin-bonded fixed partial denture technique: results of a medium-term clinical follow-up investigation. J Prosthet Dent 1993; 69: 144-148.

12) Hannson O, Bergstrom B. A longitudinal study of resinbonded prostheses. J Prosthet Dent 1996; 76: 132-139.

13) Rubo JH, Pegoraro LF, Ferreira PM. A comparison of tensile bond strengths of resin-retained prostheses made using five alloys. Int J Prosthodont 1996; 9: 277-281.

14) Aggstaller H, Beuer F, Edelhoff D, Rammelsberg P, Gernet W. Long-term clinical performance of resin-bonded fixed partial dentures with retentive preparation geometry in anterior and posterior areas. J Adhes Dent 2008; 10: 301-306.

15) Atta MO, Smith BG, Brown D. Bond strength of three chemical adhesive cements adhered to a nickel-chromium alloy for direct bonded retainers. J Prosthet Dent 1990; 63: 137-143.

16) Salonga JP, Matsumura H, Yasuda K, Yamabe Y. Bond strength of adhesive resin to three nickel-chromium alloys with varying chromium content. J Prosthet Dent 1994; 72: $582-584$.

17) Kern M, Thompson VP. Durability of resin bonds to a cobaltchromium alloy. J Dent 1995; 23: 47-54.

18) Matsumura H, Tanaka T, Taira $Y$, Atsuta M. Bonding of a cobalt-chromium alloy with acidic primers and tri- $n$ butylborane-initiated luting agents. J Prosthet Dent 1996; 76: 194-199.

19) Petrie CS, Eick JD, Williams K, Spencer P. A comparison of 3 alloy surface treatments for resin-bonded prostheses. J Prosthodont 2001; 10: 217-223.

20) O'Brien WJ. Dental materials and their selection. 4th ed. Chicago: Quintessence Publishing; 2008. p. 230-242.
21) Parsa RZ, Goldstein GR, Barrack GM, LeGeros RZ. An in vitro comparison of tensile bond strengths of noble and base metal alloys to enamel. J Prosthet Dent 2003; 90: 175-183.

22) Stoknorm R, Isidor F, Ravnholt G. Tensile bond strength of resin luting cement to a porcelain-fusing noble alloy. Int $\mathrm{J}$ Prosthodont 1996; 9: 323-330.

23) Moulin P, Degrange M, Picard B. Influence of surface treatment on adherence energy of alloys used in bonded prosthetics. J Oral Rehabil 1999; 26: 413-421.

24) Kadoma Y. Adhesive properties and kinetic polymerization behavior of resins containing adhesion promoting monomers for precious metals. Dent Mater J 2005; 24: 335-341.

25) Okuya N, Minami H, Kurashige H, Murahara S, Suzuki S, Tanaka T. Effects of metal primers on bonding of adhesive cement to noble alloys for porcelain fusing. Dent Mater $\mathrm{J}$ 2010; 29: 177-187.

26) Minami H, Murahara S, Suzuki S, Tanaka T. Effects of metal primers on the bonding of an adhesive resin cement to noble metal ceramic alloys after thermal cycling. J Prosthet Dent 2011: 106: 378-385.

27) Ozaki M, Suzuki M, Itoh K, Wakumoto S. Laser-Raman spectroscopic study of the adhesive interface between 4-MET/ MMA-TBB resin and hydroxyapatite or bovine enamel. Dent Mater J 1991; 10: 105-120.

28) Kadoma Y, Kojima K. Water durability of resin bond to precious metal alloys using adhesive resins containing adhesion promoting monomers. Dent Mater J 2005; 24: 494502.

29) Kojima K, Kadoma Y, Yamauchi J. Study on adhesive primer to dental metal used for composite type resin cement. J J Dent Mater 1997; 16: 316-321.

30) Atsu SS, Kilicarslan MA, Kucukesmen HC, Aka PS. Effect of zirconium-oxide ceramic surface treatments on the bond strength to adhesive resin. J Prosthet Dent 2006; 95: 430436.

31) Ghazy M, El-Mowafy O, Roperto R. Microleakage of porcelain and composite machined crowns cemented with self-adhesive or conventional resin cement. J Prosthodont 2010; 19: 523530.

32) Koizumi H, Nakayama D, Oba Y, Yamada K, Matsumura H. Effect of acidic primers on adhesive bonding of tri-nbutylborane initiated adhesive resin to alumina. J Oral Sci 2010; 52: 571-576. 